\title{
9 \\ Cultural Poetics and the Politics of Literature
}

\author{
Frederik Tygstrup and Isak Winkel Holm
}

In his memoirs, A Tale of Love and Darkness, published in 2004, Amos Oz tells the story of his grandmother's death. Arriving in Israel on a warm summer's day in 1933 from one of Eastern Europe's grey winter villages, she saw the hot marketplace in front of her, with its bloody carcasses, colourful fruit, sweating men and noisy vendors and passed her verdict: 'The Levant is full of microbes.' She immediately embarked on a comprehensive hygiene regime, which she zealously came to maintain over the next 50 years - a regime which included cleaning, scalding, airing and disinfecting everything, including her own body, on a daily basis. The cleaning frenzy comes to an end only when she collapses at 80 -something with heart failure during one of the three hot baths, which were part of her daily routine. So what did the grandmother die of? The fact is that she died of heart failure. But the truth is that it was her monstrous hygienic programme that killed her. And, on a philosophical tone, Oz adds: 'Facts tend to hide the truth from our eyes.' ${ }^{1}$

\section{Truths and facts}

The world is full of facts, and we are presented with still more facts at a still faster pace. For the last couple of centuries, facts have been the undisputed starting point of any knowledge. We consider facts as 'hard' and see them as a solid foundation for our ideas and actions. But the encounter with the evidence of the fact is followed by the questions of how and why this fact comes about - questions to which the fact in itself does not necessarily provide us with an answer. Facts must be organized into patterns for us to relate to them. In order to understand the grandmother's heart failure we must know about the manic cleanliness which led to the hot baths and thus put a fatal strain on her circulatory 
system. And in order to understand her manic cleanliness, we must take into account a complex set of conceptions about the East and the West, about corporeality and sensuousness, about visibility and invisibility, about control and vulnerability and so on. The truth Amos Oz is seeking does not immediately follow from the facts, it only begins to emerge when a host of such diverse secondary circumstances - material, psychological, historical or cultural factors - are combined with the facts in that specific configuration which for him is able to capture the grandmother's story.

The facts in place, the true image of reality is still to be produced. This production of images of reality can be considered both on a small and on a large scale. On the small scale it could be a matter of an author's configuration of facts into a coherent shape by telling stories or setting up complex metaphorical patterns. According to $\mathrm{Oz}$, writing a novel is like building a full model of a city from matches - complete with buildings, squares, boulevards, towers and suburbs, down to the smallest bench. ${ }^{2}$ And it is the consistency of the model that enables us to understand the individual element. Today, when facts are accessible to us on an unprecedented scale, Oz suggests, our need is greater than ever for fictions and narratives that can provide the facts with a world in which they make sense.

On a larger scale, a culture similarly produces collective images of reality by capturing facts and integrating them into interpretive frameworks, quite like the work of the individual author. Any culture possesses a common set of models prescribing our ways of seeing, of thinking and of relating to ourselves, to each other and to the shared surroundings. Living in a culture very much amounts to having acquired this common repertoire of narratives and cognitive forms that can be used to configure facts. These collective techniques and principles enabling the production of cultural images of reality may be called, with Louis Montrose's felicitous term, a 'cultural poetics'. ${ }^{3}$

We never create our individual frameworks of understanding in a cultural vacuum. In each case, a cultural poetics will be at hand with a series of suggestions for already existing ways in which to frame a fact. An individual fact may be spectacular, unprecedented or peculiar; but the mere inertia of the familiar cultural repertoire of accepted truths and explanatory models will more often than not reassure us that the fact can be identified with something we already know. In such cases the situation is virtually the opposite of the one diagnosed by Amos Oz: here it is no longer the facts that obscure the truth, but rather the already established truths which conceal or mask the singularity of a given fact. 


\section{PROOF}

Frederik Tygstrup and Isak Winkel Holm 201

In this sense, cultural poetics not only offers to arrange the facts and render them comprehensible in a neutral manner; cultural poetics produces facts. It indicates and determines what is a fact and what is not, thereby constituting a cognitive window on reality through which certain facts are accessible and others remain outside the field of vision. In the light of a given cultural regime of truth, facts may be meaningless, inconceivable, frivolous or heretical; consequently, they will remain in the dark. The cultural poetics constitutes a system of inclusion that captures facts and gives them an explanation and a framework, but it also constitutes a system of exclusion that determines what can rightfully be perceived as a fact, and what should be excluded from this category. Michel Foucault highlighted this historical mechanism of exclusion in his comments on Mendel's theory of heredity; Mendel introduced a concept of hereditary features which did not correspond to any existing scientific categories, and whose function broke with contemporary conceptions about reproduction. What Mendel said was true, Foucault remarks, but it was not 'within the truth': that is, not in accordance with the model for biological scientific truth subscribed to by his contemporaries. ${ }^{4}$

If an author wants to give a true image of reality, then, siding with the truth against the contemporary avalanche of facts is not enough. In order to say something true, one may also have to break out of the truth of one's contemporaries. When Salman Rushdie, in The Satanic Verses, refers to a city which is 'visible, but unseen', 5 he sides with the facts against the received truths. Rushdie's implication is that in a modern metropolis, there are so many facts and so many complicated relations between them about which we know very little, because we prefer to decipher and understand the world in the same way as generations before us. Even if this wonderfully complex urban reality is visible to anyone, it nonetheless remains unseen, simply because we do not possess an adequate way of viewing it. Our cultural poetics has not trained us sufficiently to actually see what is visible. Here the facts challenge the truth, and the task of the author is, thus, to highlight facts and to insist on focusing on them until it actually becomes possible to see them.

Amos Oz defends truth against facts; Salman Rushdie defends facts against truth. Nonetheless, the two authors have a common concern, namely an interest for how literature may create an effective image of reality in the continuous friction between truths and facts, between cultural knowledge and practical experience. In this, the two novelists pose the classic question of representation. Literary studies have traditionally 
discussed this question using concepts such as mimesis, realism and reflection. Representation is not only the concern of literary scholars, however, but exists in the two formats described above, as a literary poetics and a cultural poetics. Literary poetics concerns the techniques used to represent reality within the relatively narrow confines of literature. In contrast, cultural poetics describes the pervasive principles for interpreting reality which apply across the different spheres and institutions of a society. Whereas the literary poetics is typically characterized by a sharply focused individual intention, the cultural poetics is, rather, an anonymous collective work without a distinct sender. Seen from the perspective of representation theory, however, the two poetics work in much the same manner: both are engaged in creating forms that can make a changing reality accessible to thought and action.

In the following, we will describe the position of literature in relation to 'the political' by discussing the interaction between literary poetics and cultural poetics. First, we will characterize the cultural poetics more precisely through the concept of 'symbolic forms'. Second, we will focus on the literary poetics and its institutional context. And finally, in a third step, we will take a closer look at the interaction between literary and cultural poetics.

\section{Symbolic forms}

In philosophy, the discussion about truths and facts is often identified with the quarrels between rationalist and empiricist thinkers in the eighteenth century about the foundation for knowledge, either in the indisputable truths of reason, as rationalists have it, or in the facts of empirical observation. And it is in Kant's twofold critique of his predecessors that we find the first contours of the problem of representation outlined above. To Kant, the essential is neither truths nor facts, but rather the laborious production of images of reality that takes place in the space between them. According to Kant, cognitive experience is a process configuring the material of sensory perception in such a way that it forms a meaningful unity. And this process follows specific procedures. The work of combining the categories of reason with the phenomena of intuition is regulated by a series of recipes for how the manifold in the sensuous intuition can be assembled into a unity. Using a modern metaphor, we may say that, according to Kant, human consciousness is equipped with its own unique operating system that sets the conditions for how categories and phenomena can be made coherent. 


\section{PROOF}

Frederik Tygstrup and Isak Winkel Holm 203

In Critique of Pure Reason, Kant explains that the transcendental operating system consists not only of categories, but also of figures. Cognition relies on a type of pure, abstract figures, which Kant calls schemata. The schema is a figment of the productive imagination enabling a conceptual grip of the manifold of the sensuous intuition. It is a 'monogram', a figurative matrix for the combination of the sensuous diversity issuing from perception. In Kant's words, our use of such transcendental forms 'is a hidden art in the depths of the human soul, whose true operations we can divine from nature and lay unveiled before our eyes only with difficulty'. ${ }^{6}$

Unfortunately, Kant does not elaborate on the schematism of reason. The mapping of this hidden art was only performed 140 years after the publication of Critique of Pure Reason, by Ernst Cassirer in The Philosophy of Symbolic Forms. Like Kant, Cassirer argues that a workable image of reality should be based neither on the concepts of reason or the data of perception, but should be built in the field between them. However, according to Cassirer, schematism should not be understood in a purely logical manner, as Kant would have it; it must be understood historically, on the basis of the actual historical images of reality that can be uncovered by the study of cultural history. While thus historicizing the Kantian critique of knowledge, Cassirer at the same time reverses the Kantian conceptual hierarchy. For Kant, the starting point was the rational concepts and the sensual perceptions that had to be fused in the magic of intuition. For Cassirer, things work the other way round: his starting point is the existence of human images of reality, which are used as a basis for reconstructing certain conceptual systems and sensory forms of attention.

Cassirer's term for such images of reality is 'symbolic forms'. Symbolic forms constitute a historical schematism that operates as the transcendental condition of possibility for the interpretation of reality in a specific culture. 'Cultural poetics' can thus be understood as a specific historical regime of symbolic forms. Symbolic forms is a cultural repertoire of mental models allowing us to assess reality and thus to deal with it pragmatically in everyday life. Symbolic forms differ widely in terms of their scale and scope; as shorthand examples, we can consider the confession as a symbolic form which makes it possible to form an image of a person's intimate life; the diagnosis as a symbolic form which regulates the understanding of the relationship between the normal and the pathological; or the social contract as a formula which sets up rules for human relationships.

To engage in an analysis of symbolic forms, Cassirer takes the actual historical cultural practice as his starting point. He explores the 
concrete ways in which reality, in specific places and at specific times, has been described by those experiencing it. On this point, Cassirer shares a conviction with the German Geistesgeschichte of his time: that a given culture should be understood from within, in the light of its actual values, insights and practices, rather than from the outside, through some general principles of description. At the same time, though, the cultural history of symbolic forms also differs from Geistesgeschichte by way of its materialism. For Cassirer, the ambition is not to reconstruct a mental landscape of ideas and intuitions, but to piece together an actual textual and visual archive of historical images of reality. In other words, Cassirer's subject matter is not ideas about reality, but representations of reality. For instance, the important thing is not the confession as an underlying mental template, but, rather, the plethora of actual confessions in their available textual manifestations.

The philosophy of symbolic forms also displays a striking similarity with another feature of Geistesgeschichte, namely a strong tendency to homogenize the image of a culture by focusing on cohesion and totality rather than on contrasts and confrontation. As a corrective, one might reiterate Marx's point - put forward in The Eighteenth Brumaire of Louis Bonaparte - that an image of reality does not necessarily include all the different potential perspectives on this reality. Darstellung is not the same as Vertretung; representations of reality are not necessarily representative of the represented reality. ${ }^{7}$ In other words, the validity and impact of a cultural system of symbolic forms will remain determined by a social order of power and social interests. Power relations are involved in the favouring of certain ways of thinking, speaking and acting; and in the exclusion of others as meaningless or trivial. A repertoire of symbolic forms offers the opportunity to make a range of different utterances, but not all of these will be perceived as meaningful and representative statements about the order of things. Seen in this light, the social struggle between different interests and social groups can be described as a struggle between ways of forging images of what reality looks like and what it ought to look like. This conflictual aspect is attenuated in Cassirer's description of rather homogeneous cultural totalities, whereas Italian political philosopher Antonio Gramsci's concept of hegemony helps keep it in focus. Symbolic forms are hegemonic when their way of representing reality serves the interests of the dominant powers. ${ }^{8}$

The political dimension of symbolic representations of reality is not only visible in this massive, agonistic sense, however, where class interests are lined up in confrontation to seek hegemony for their own interpretation of the world. The poetics of culture is played out in 


\section{PROOF}

Frederik Tygstrup and Isak Winkel Holm 205

the public arena where political ideologies, works of art and scientific hypotheses are presented; it also lies at the basis of the individual's everyday life at work and in private contexts. The specific models for how the things of the world can be configured also determine how objects and people are categorized in the intimate and private spheres of human life, as well as in society at large. In this sense, the political is omnipresent and by no means limited to the 'political' topics discussed in newspapers and in parliamentary assemblies. This insight can be captured by Jacques Rancière's concept of the division of the sensible. Rancière's 'partage du sensible' is a name for the basic order of things, the 'a priori forms' - as he puts it with specific reference to Kant - 'which determine what presents itself to sensory perception and defines the coordinates for time and space, as well as for what can be said and what can be seen'. ${ }^{9}$

Finally, the poetics of culture is not only a question of rational knowledge, but also of desire. The repertoire of symbolic forms is not only a toolbox of antiseptic instruments designed to deal with the world in an objective manner; it is also a billowing veil of fascinations, dreams, aversions and idealizations. A cultural poetics can produce wonderfully meaningful and coherent images of reality by projections of desire and paranoid illusions. Desire distorts the cultural filter of modes of imagination and ways of thinking, which means that the images of reality contain patches of both inexplicable blindness and hysterical sharpness. This insight is highlighted in Slavoj Žižek's concept of unconscious ideological fantasy. In Žižek's Lacanian optics the collective fantasies function as the condition of possibility for the ability to perceive, act within and talk about the surrounding society. He talks about the sociosynthetic function of fantasy, and the formulation has clear roots in Kant's theory of cognition. The same goes for Žižek's characterisation of these fantasies as a formal-transcendental a priori. ${ }^{10}$

The symbolic forms constitute the hidden art - not in the depths of the human soul, as Kant put it, but in the depths of human culture. This hidden art is a vital part of the political. In the common sense of the term, the political covers the familiar game of views and values, of conflicts and connections. In a wider sense, however, it also includes the images of reality that determine what social issues and what social conflicts are perceived as pressing reality. Cultural poetics is a political poetics, insofar as it creates specific images of social reality and in the same process elides other facets of reality. In other words, politics is not just the art of the possible, it is also the hidden art which makes it possible to perceive of the real in the first place. 


\section{PROOF}

\section{The politics of literature}

The poetics of literature is simultaneously part of and apart from the poetics of culture. Literary poetics is a part of cultural poetics, because it contributes to the production of images of reality that can serve as models for other claims to an understanding of the world. On this level, there is no essential difference between literature and other symbolic forms. To be sure, one can easily distinguish between a tragedy in blank verse and the minutes from a board meeting, or between a sonnet and a feature article, but this is due to the existence of traditionalized genre markers rather than to any ontological features pertaining specifically to literature. Fundamentally, it is really the same - and remarkably limited - repertoire of cognitive models that functions across the various cultural spheres and institutions. For example, the confession has played an important role in the literary autobiography since Augustine, but the same symbolic form is also found in the confessional, in the interrogation room, in psychotherapy, in the television show, in the conversations struck up in a pub.

At the same time, though, literary poetics is not only part of, but also apart from the cultural poetics. When it is possible to distinguish quite easily between literary and non-literary utterances, it is because individual linguistic phenomena not only have a form, but also a framework. This framework is an institutional regulation of the social function of different utterances in respect to how they are produced, how they circulate and how they are used. The institutional framework puts the symbolic forms to work by using them as tools in a given social web of power relations and political interests. In the Catholic Church the confession serves a strictly defined purpose; in the modern legal system the confession has a different, although no less specific function.

Literature is distinctive due to its framework, not to its form. From a sociological point of view, literature is an institutionalized social field with its own rules, its own economy and a particular societal existence. The literary institution is a conglomerate of social routines, including the production, distribution and consumption of literature, and a vital part of this institution is a collective agreement to regard certain texts with a specific attitude of mind. This agreement is normally confirmed by endowing these texts with certain material, so-called 'paraliterary' markers, through which they can be recognized. The institutionally empowered convention gives these texts the status of 'fiction' - that is, texts whose pragmatic and referential functions differ from other texts. 


\section{PROOF}

Frederik Tygstrup and Isak Winkel Holm 207

Jacques Derrida has captured this problem by describing literature as both a fictional institution and an institutionalized fiction. ${ }^{11}$

The institutionalization of fiction establishes a crucial distance to the surrounding cultural poetics by suspending any unambiguously pragmatic function; utterances that circulate within the literary institution have no clearly defined social significance and impact. This institutional distance enables literature to adopt a non-pragmatic and non-intentional relationship to the reality it depicts. The literary poetics may draw on the same symbolic forms as the surrounding cultural poetics, but when these forms appear in literature, they appear suspended and without any clearly assignable accountability. Rousseau, Dostoyevsky, Camus and Coetzee do not make use of the confession for the purpose of having a particular individual judged or initiating a specific therapeutic process.

On the level of symbolic forms, to sum up, literary poetics is part of a cultural poetics, but on the level of the institutional framework, the two poetics part company. Literary images of reality generally make use of the same symbolic forms as other cultural interpretations of reality, but in a different manner. Thanks to this duality of likeness and difference, literature takes the guise of a cultural laboratory where experiments can be conducted, testing, as it were, different roles and functions of a cultural repertoire of images of reality. Paradoxically, literature's irresponsible distance to society is a condition for its ability to intervene in the life of society, not necessarily by voicing specific political views, but rather by reflecting, varying and contesting the dominant cultural poetics' division of the sensible.

The same line of thought can be expressed by saying that literature deviates from the way in which cultural images of reality are generally produced. In twentieth-century literary theory, the concept of deviation - described as alienation, defamiliarization, transgression, estrangement and so forth - has been among the most important bids for identifying the so-called literariness that sets literary language apart. According to this theory, literary images of reality differ from the more automatised representations of reality in society at large. Theories of deviation usually deal with stylistic parallelisms and metaphorical paradoxes, but literary deviation takes place not only on the linguistic level; deviation also operates on a more fundamental level that concerns the cognitive schemata through which an image of reality is produced. Literature can transform not only the stylistic form, but also the underlying symbolic form of a representational routine. Due to its institutionally sanctioned distance to the pragmatics of social life, 


\section{PROOF}

literature can defy our everyday and habitual - and therefore hidden ways of constructing images of reality.

\section{Creation, exposition, transposition}

On a general note, we will propose to distinguish between three different modes of deviation on the level of symbolic forms (modes which can, of course, overlap and appear side by side in a literary work). First, deviation can take the shape of a creation of new images of reality that challenge a dominant regime of symbolic forms. Since the material of literary representation of reality is always a historical language, the creation of new models is always an adaptation of existing models, a constructive reorganizing of pre-existing material. Here, deviation operates a de-formation and trans-formation of prevalent ways of constructing images of reality. Fiction here serves to think and show something that does not naturally fall within the habitually conceived order of things. This attitude was the starting point for both Amos $\mathrm{Oz}$ and Salman Rushdie, circling about something they want to express, as it were - how the grandmother's life is reflected in her death, how different mental universes converge in creating a specific spatial quality - but which cannot be grasped with the available modes of explanation and description. In order to approach aspects of reality that would otherwise have remained silent, they must write new stories, invent new forms of description. Giving a voice to a truth about a singular life or a singular event requires that an aspect of reality be liberated from the standard cultural repertoire of themes and forms. What is required, in other words, is the creation of a specific and unheard-of configuration of events, emotions and viewpoints capable of grasping the way in which the singular deviates from the general.

Literature creates experimental models of reality. These experiments originate in the singular: the concrete configuration of forms, of lines, colours, shapes, sounds or words. Oz's image of the grandmother springs from a single statement: 'The Levant is full of microbes'; Rushdie's image of the city starts with an encounter on a street corner. The singular artistic starting point opens up a potential window on the world. By composing an image of the world from this viewpoint, the work of art is able to not only describe and account for the individual situation - how the grandmother's life converges and makes sense in the light of the simple statement - but also to create a far more comprehensive explication of reality. To the extent that an image of the 'visible, but unseen' reality is successfully created, an entire image of 


\section{PROOF}

Frederik Tygstrup and Isak Winkel Holm 209

a world emerges. How do Israeli everyday life, political life and mental universes look in the light of the grandmother's life story, as told by $\mathrm{Oz}$ ? Or, how can we observe the postcolonial city as a conglomerate of material, mental and social layers?

Literature's capacity to create new models of reality enables it to alert its readers to hitherto unseen aspects of social reality. Literature has rendered visible the reading and writing daughters of the bourgeoisie in the eighteenth century, the entrepreneurial third class in the nineteenth century, industrial mass societies in the first half of the twentieth century, and the postcolonial migrants from the 1950s and today. The artwork's division of the sensible begins in the configuration of the single image, of the single perceptual starting point, but the division has a potential and wide-reaching resonance in the work, in the reader, in tradition and in social life.

Second, the deviation can take the shape of an exposition of a culture's repertoire of images of reality. From this perspective, literature is not only a laboratory for the creation and transformation of symbolic forms, it is also a medium capable of rendering existing forms visible. The exposition can be regarded as a sort of citation of existing images of reality, and as such it can take many different forms, from direct citations of historical uses of language to reconstructions of 'typical' images of reality. In his works on realism, Georg Lukács formulated a concept of 'the typical', inspired by Max Weber's sociological concept of the ideal type. To Weber, the typical did not necessarily constitute something that is typical in a statistical sense; rather, it summarizes some essential features that are not likely to be matched by any empirical findings. For Lukács, the successful realistic character description was typical in this sense, as found, for example, in Balzac's works, which included the typical banker, the typical journalist, the typical countess and so forth. The typical characters of Balzac's novels gave a convincing impression of being real, because they were provided with an abundance of such individual oddities and peculiarities that are typical of the individual. ${ }^{12}$

A corresponding form of literary typicality is found on the level of symbolic forms, where the typical summarizes some essential features of a culture's way of understanding existential, social or material reality. Against this background, the technique of exposition can be described as an art of characterization by means of which the author does not modify, but rather condenses salient forms of a historically situated cultural poetics. This is the case when Flaubert cites the conventional language of the cattle show intertwined with the equally conventional language of the love encounter, when Hermann Broch, in The Sleepwalkers, cites 
the language of the public house, or when Chuck Palahniuk cites the language of sexual therapy. In these instances, the exposition of images of reality has replaced the functional pragmatics of the image of reality. When the symbolic forms of a culture are not only applied, but also exposed, transformed into typifying quotations, the invisible quotation marks around them become visible. The words and sentences appear as if surrounded by a fine luminous edge, like an ethnographical object in a display case. This is the alienating effect of the expository function, namely the making visible of the symbolic forms as what they are: flawed conventions upon which we depend heavily for our perception of reality. Most often, the hidden art is buried in the depths of human culture, but sometimes, literature is capable of unearthing this deeply hidden art, putting it on display and making it subject to debate.

Third, and finally, the literary deviation can take the shape of transposition of an image of reality from one institutional context to another. The transposition consists in moving a symbolic form across the boundary between the literary and the cultural poetics, thus negotiating the existing boundaries between literature and the social institutions surrounding it.

The most obvious example is the question of censorship. From the trials against Flaubert and Baudelaire to the fatwa against Salman Rushdie, a standard argument in the fight against censorship has been that the statements found in literature cannot be assessed in the same manner as the social and political statements circulating outside the literary institution. This strategy positions itself on the fine line separating between cultural and literary poetics. The image of reality - an unfaithful provincial wife or a boozing prophet - makes perfect sense on both sides of the boundary, but with dramatic differences. Is the image of Emma Bovary a celebration of a promiscuous provincial wife or a diagnosis of how wrong things can go for someone who is bored by provincial life (as Flaubert, somewhat hypocritically, claimed during the trial)? Is the image of the prophet an accusation directed at a historical person for indulging in dubious moral conduct, or does it present the impression of Muhammad of a delirious mind of the late twentieth century?

The transposition of an image of reality creates an effect of defamiliarization, merely through the change of context. One may try, for example, as Robert Musil once suggested, to quote a poem at a general assembly, or to place a crystal glass on a ploughed field. ${ }^{13}$ Alienation effects of this type are not only something literature is more or less unfairly subjected to, as in cases of censorship; it is also something literature has been able to exploit. Literature can intervene directly in 


\section{PROOF}

Frederik Tygstrup and Isak Winkel Holm 211

political affairs and discussions, it can be agitational and polemical, and it can articulate directly political positions - while enjoying the protection of its special status as literature. Thus, what literature says in relation to a political context remains unsaid in a certain sense, since it is protected by the attenuating suspension mechanisms of the literary institution. On the other hand, the system of attenuation has regularly annoyed authors eager to intervene because the subduing of resonance also means that the effect of any literary political intervention is relatively modest.

In our general overview we have outlined three forms of deviation, all of which exploit the boundary between literary and cultural poetics and indeed the fact that literary poetics is simultaneously both a part of and apart from cultural poetics. The creation of fictional world models uses the privileged enclosure of the literary institution to deform and transform existing symbolic forms in the endeavour to think and show something that does not naturally fall within the given order of things. Here, literature is an eminently realistic undertaking in the sense that it tries to capture pieces of reality that haven't yet been named properly. The exposition of typical epistemic models and the exploration of their social function uses aesthetic distance to make evident the devices and social interests invested in the model in question. In this case, literature is realistic by reflecting and communicating existing historical images of reality. Transposition, finally, allows the literary models of reality to go beyond and question the institutional framework of literature. Here, literature is realistic insofar as it exceeds the boundary between fiction and reality and engages directly in political reality. The first two strategies of deviation - creation and exposition - depend on a reasonably stable boundary between literary and cultural poetics insofar as their thinking and showing of the world take place within an institution. In these cases, literature is political precisely by virtue of its status as literature. In contrast, in the third strategy of deviation, literature is political by exceeding this boundary and thus undermining its own status as literature.

The boundary dividing literary and cultural poetics has obviously been in constant flux since what we today agree to call literature was given a fairly well-defined institutional framework in the course of the eighteenth century. At times, literature has commanded great impact and been highly influential; at other times, it has remained socially rather insignificant. It has been tied to dominant ideological discourses, and to oppositional or suppressed ones; it has been closely connected to the consolidation of new historical identities, and it has withdrawn 


\section{PROOF}

\section{Cultural Poetics and the Politics of Literature}

from all social interaction. In each of these cases, the actual exchange between literature as an institutionalized activity and the surrounding world has been renegotiated, and new boundaries have been drawn. Each new renegotiation can be described as a deviation questioning the functions, the forms and the possibilities of literary writing. Put differently, each work of literature relates, explicitly or implicitly, strategically or pragmatically, to its mode of existence as literature.

The boundary between literary and cultural poetics currently seems to be the subject of particularly lively negotiation. The fatwa against Salman Rushdie in 1989 may be taken as a symptom of this. In a Western context, the practising of religion has over the past couple of centuries taken place within a specific institutional context tied to the church and the private sphere, reasonably clearly separated from other contexts of social action. The fatwa suddenly introduced a religiously founded injunction, thus cutting right through the division between the religious, the social, the political and the literary, suspending all the differentiated transposition mechanisms.

This may indicate that the boundary between literary and cultural poetics is no longer upheld as something entirely robust, and that the current mixtures - not only of religion and politics, but also of politics and 'identity', of politics and advertising, of political interests and economic interests and, in a wider sense, of social production, consumption and reproduction - mark a new challenge in terms of the way literary practice should handle the boundary between literature and society at large. The documentary film genre is perhaps the art form that has most consistently exploited this transposition from 'fictional' images of reality to 'documentary' ones and vice versa. Similarly, literature also seems to challenge still more radically the boundary which defines it as literature - or 'mere literature' - and thus to be holding an altered literary practice up against the current destabilization or de-differentiation of the institutional boundaries of social life. Perhaps literature is becoming political in a new way: not as a question of the author's correct or incorrect views, but as a reaction to - and an exploitation of - the fact that the boundary between the literary and cultural poetics is undergoing rapid change: in other words, a politicization that not only stems from the practice of literary writing, but also from its mode of existence in society. This seems to have brought about a new form of involvement and a new creative impetus in literature, currently transporting images of reality and models for the construction of images of reality across the boundary between the two poetics. It is, not least, this development 


\section{PROOF}

Frederik Tygstrup and Isak Winkel Holm 213

which prompts renewed reflection on the relationship between the poetics of culture and the poetics of literature.

Translated by Lise Utne

\section{Notes}

1. Amos Oz, A Tale of Love and Darkness, trans. Nicholas de Lange (Orlando: Harcourt, 2004), 45.

2. Ibid., 331.

3. Louis Montrose, 'The Poetics and Politics of Culture', in The New Historicism, ed. H. Aram Veeser (London: Routledge, 1989), 15ff.

4. Michel Foucault, L'Ordre du discours (Paris: Gallimard, 1971), 37.

5. Salman Rushdie, The Satanic Verses (New York: Viking, 1988), 241.

6. Immanuel Kant, Critique of Pure Reason, trans. and ed. Paul Guyer (Cambridge: Cambridge University Press, 1998), B180.

7. See also Ernesto Laclau, 'Power and Representation', in Laclau (ed.), Emancipations (London: Verso, 1996), 84ff.

8. See Chantal Mouffe, On The Political (London: Routledge, 2005), 17ff.

9. Jacques Rancière, Le partage du sensible (Paris: La Fabrique, 2000), 13.

10. Slavoj Žižek, The Sublime Object of Ideology (London: Verso, 1989), 17 and 20.

11. Derek Attridge, 'This Strange Institution Called Literature: An Interview with Jacques Derrida', in Acts of Literature (New York: Routledge, 1992), 36.

12. Georg Lukács, 'Verlorene Illusionen', in Balzac und der französische Realismus, Werke, vol. 6 (Neuwied: Luchterhand, 1965), 478ff.

13. Robert Musil, The Man Without Qualities, trans. Eithne Wilkins and Ernst Kaiser (New York: Perigee, 1980), vol. 1, 231. 